\title{
Prospects of Tectona Grandis as a Feedstock for Biodiesel
}

\author{
Amit Sarin ${ }^{1 *}$, Meetu Singh ${ }^{2}$, Neerja Sharma ${ }^{3}$ and N. P. Singh ${ }^{4}$ \\ ${ }^{1}$ Department of Physical Sciences, I.K. Gujral Punjab Technical University, Kapurthala, India, ${ }^{2}$ Department of Applied \\ Sciences, I.K. Gujral Punjab Technical University, Kapurthala, India, ${ }^{3}$ PG Department of Physics and Electronics, DAV \\ College, Amritsar, India, ${ }^{4}$ Department of Planning and External Development, I.K. Gujral Punjab Technical University, \\ Kapurthala, India
}

The limited availability of fossil fuels has encouraged the need of replacement fuels of renewable nature. Among the renewable fuels, biodiesel produced from oil seeds and food wastes has been favored by the majority of researchers. In this study, Tectona Grandis seed oil has been investigated as a non-edible feedstock for biodiesel. The oil content of seed is $43 \%$ which makes it suitable for commercial production of biodiesel.

OPEN ACCESS

Edited by:

Liandong Zhu,

University of Vaasa, Finland

Reviewed by:

Jinxue Jiang,

Washington State University,

United States

Baskar Gurunathan,

St. Joseph's College of Engineering,

India

István Barabás,

Technical University of Cluj-Napoca,

Romania

Perumal Varalakshmi,

Madurai Kamaraj University, India

*Correspondence:

Amit Sarin

amit.sarin@yahoo.com

Specialty section:

This article was submitted to

Bioenergy and Biofuels,

a section of the journal

Frontiers in Energy Research

Received: 15 August 2017

Accepted: 04 October 2017

Published: 26 October 2017

Citation:

Sarin A, Singh M, Sharma N and Singh NP (2017) Prospects of Tectona Grandis as

a Feedstock for Biodiesel.

Front. Energy Res. 5:28.

doi: 10.3389/fenrg.2017.00028
The synthesis of biodiesel from $T$. Grandis oil was done with transesterification reaction giving high percentage yield of biodiesel which reached to 89\%. The T. Grandis biodiesel was subjected to determine various physicochemical parameters by standard testing methods and found in agreement with the ASTM D-6751 and EN-14214 standards. The fatty-acid methyl ester composition for the biodiesel is composed of $42.71 \%$ oleic acid, $13.1 \%$ palmitic acid, and $31.51 \%$ linoleic acid. The biodiesel showed low oxidation stability which is attributed to high percentage of unsaturation. To address this issue, synthetic antioxidants were added to increase its resistance towards oxidation. By considering all the parameters, the present study reveals that $T$. Grandis seed oil is reliable for the production of biodiesel with encouraging probability in future.

Keywords: biodiesel, feedstock, Tectona Grandis, transesterification, physicochemical properties

\section{INTRODUCTION}

The energy generated from the combustion of fossil fuels has indeed enabled many technological advancements and social-economic growth. However, the increasing demand of energy and environmental concerns arising due to the use of traditional fuels has become a threat to the sustainability of our ecosystem and sparked the need of energy sources of limitless duration with a smaller environmental impact. Biodiesel falls in the category of such fuels of renewable nature (Hu et al., 2004; Gui et al., 2008; Ullah et al., 2014). To address the issues related to pollution with petro-based fuels, Government of India has taken steps toward usage of biofuels. In this context, the Ministry of New and Renewable Energy has proposed 20\% blending of transportation fuels, namely, diesel and petrol with bioethanol and biodiesel as a national biofuels policy by 2017 (Government of India, 2009). However, the contribution of energy from biomass has been estimated as one fourth of global energy by 2050 (Hossain and Davies, 2013).

The role of feedstock is significant for the characteristics and cost of any biodiesel. The possible feedstock for biodiesel production broadly categorized as edible and non-edible. Edible feedstocks such as soybean, palm, and sunflower are considered to be first-generation biodiesel feedstock because they were the first crops to be used to produce biodiesel and non-edible feedstock such as jatropha, mahua, jojoba oil, salmon oil, sea mango, waste cooking oils, and animal fats are considered 
to be the second-generation feedstocks (Najafi et al., 2011; Sarin, 2012). The emerging work on feedstock for the biodiesels includes camelina, Hevea brasiliensis and Ricinus communis, Virginia-type peanut, Moringa oleifera, etc., reflects the need to explore other feedstock which can show compatibility with environment, farming, cost, and food security of any nation (Fernandes et al., 2015; Silitonga et al., 2016; Silveira et al., 2016; Yang et al., 2017).

Among various alternative feedstocks, the most studied and employed feedstock in India is Jatropha curcas but its commercial viability is transient (Contran et al., 2013). In order to provide versatility in the formulation of biodiesel, it is necessary to explore more alternate feedstock to establish a concrete approach toward energy sector. The present research work is an attempt to investigate the potential of Tectona Grandis (TG) seeds as feedstock for biodiesel. Tectona Grandis, commonly known as Jatus Grandis, Teak, or Sagwan, is a large, deciduous tree in favorable conditions. It can survive under a broad range of climatic ambiance. It grows best in a warm, moist, tropical climate with a significant difference between dry and wet seasons. It is native to India, Indonesia, Myanmar, and Southeast Asian countries (Keiding et al., 1986). It is emerging as one of the important species of tropical plantation forestry. The cultivation of TG supports the ecosystem by beautifying the environment, aerating the atmosphere, and preventing erosion. Wood from this tree has been used in the formation of charcoal and fuel wood since a long time (Kjaer et al., 1995). Many reports have claimed the medicinal use of leaves and fruit of TG tree. The authors performed an experiment to obtain the biodiesel from the oil of non-edible TG seeds, which has never been undertaken before. The sustainable production of vegetable oil for biodiesel production from a tree crop such as TG, which can be cultivated on marginal land, has the potential to not only provide a renewable energy resource but also may alleviate the competitive situation that exists due to food versus fuel issue, and it further ensures the utilization of every part of plant to furnish the economic viability (Singh et al., 1996; Akmal and Karvekar, 2010). The mission of Indian Government is to put focus on progressive blending and substitution of fossil fuels such as petrol and diesel with greener fuels like biodiesel. Therefore, keeping such missions on priority and to support the growth of bioenergy sector, authors have undertaken studies to assess the prospective of tree-borne non-edible oil from TG seeds, as a feedstock for biodiesel. Although there are numerous publications on various feedstocks for biodiesels along with their storage conditions, stability, and effect of antioxidants, none is available on TG biodiesel. This study aims to investigate the potential of TG oil as feedstock for biodiesel. This paper also focuses on factors to enhance the oxidation stability of tectona methyl ester (TME).

\section{MATERIALS AND METHODS}

\section{Materials}

Tectona Grandis seed kernels were collected from campus of Amritsar College of Engineering and Technology, Amritsar (India) which have been dried and grounded for better oil extraction. All chemical reagents purchased from Sigma-Aldrich were of analytical grade.

\section{Oil Extraction}

The grounded specimen was put in a soxhlet extractor having $n$-hexane as solvent. It was kept for $6-7 \mathrm{~h}$. The obtained oil was then treated to reflux the hexane at $65-70^{\circ} \mathrm{C}$ and brownish teak seed oil was recovered for further studies (Fernandez et al., 2015). After extraction of oil from seeds, acid value and free fatty-acid content of oil has been investigated to follow feasible transesterification criteria. The percentage of oil yield was calculated by using the following formula:

$$
\text { Oil yield }(\text { in } \%)=\frac{\text { weight of oil extracted }}{\text { weight of kernels used }} \times 100 \text {. }
$$

\section{Transesterification for Biodiesel Production}

Biodiesel from crude TG oil was carried out by transesterification process, involving reaction of oil with methanol under reflux conditions (Chen et al., 2012; Lin et al., 2014). Homogeneous transesterification process was performed after investigating the free fatty-acid content of TG oil which was less than unity. Methanol (1:6 $\mathrm{M}$ ratio to oil) was separately added to the sodium methoxide as catalyst ( $0.75 \mathrm{wt} \%$ of oil) and stirred until the complete dissolution of catalyst in methanol (KoohiKamali et al., 2012). The above-stirred solution was added to TG oil in reactor and the reaction temperature was set at $65^{\circ} \mathrm{C}$. The stirring of mixture was carried out for $1 \mathrm{~h}$ at $400 \mathrm{rpm}$. After completion of the reaction, the material was transferred to separating funnel and kept overnight to settle down, which results in the formation of two phases. Upper phase was tectona methyl ester (biodiesel) and lower part was glycerin. TME was then washed with warm water four to five times to remove the traces of glycerin, unreacted catalyst, and soap formed during the transesterification (da Silva et al., 2017).

\section{Physicochemical Properties and Fatty- Acid Methyl Ester Composition}

To check the feasibility of TME as an alternative fuel, its fatty-acid methyl ester composition and physiochemical properties were analyzed as per ASTM D-6751 and EN-14214 specifications (Sarin et al., 2010; Lane et al., 2012).

The synthesized TME was tested for physicochemical properties such as acid value, viscosity, cetane number, oxidation stability, calorific value, cold flow properties, flash point, iodine value, density, refractive index, and other considerable characteristics by standard methods. Acid number or neutralization number is a measure of the amount of free fatty acids contained in a fresh fuel sample. It is indicated in milligram $\mathrm{KOH}$ required to neutralize $1 \mathrm{~g}$ of FAME. The sample is dissolved in a mixture of toluene and propan-2-ol containing a small amount of water and titrated potentiometrically against $\mathrm{KOH}$. Acid number is measured according to EN-14104 and ASTM D-664 where it is limited to $0.5 \mathrm{mg} \mathrm{KOH}$ per gram. Low-temperature properties are indicated by the cloud point (CP), pour point (PP), and cold filter plugging point (CFPP) of the fuel. Using standard testing methods, CP is measured according to EN-ISO 23015, ASTM D-6751, and ASTM D-2500; PP is measured according to EN-ISO 3016, ASTM D-6751, and ASTM D-97; and CFPP is measured 
according to EN-14214, EN-116, and ASTM D-6751 and ASTM D-6371. Kinematic viscosity is a measure of resistance to flow of a liquid due to internal friction. It is measured according to the EN-ISO 3104 and ASTM D-445 specifications, which are limited to $3.5-5.0 \mathrm{~mm}^{2} \mathrm{~s}^{-1}$ and $1.9-6.0 \mathrm{~mm}^{2} \mathrm{~s}^{-1}$, respectively. The oxidation stability of biodiesel was studied by using 893 professional Biodiesel Rancimat equipment (Metrohm, Switzerland) according to the EN-14112 and ASTM D-6751 specifications. The other considerable physicochemical properties were characterized by standard methods. Although the biodiesel prepared from TG oil meets most of the specifications, it is failed to meet oxidation stability standard of $6 \mathrm{~h}$ specified by EN-14214. This issue was addressed by blending biodiesel with synthetic antioxidants to increase its resistance to oxidation. The study examined the efficacy of four synthetic antioxidants added in different levels of concentration: namely, butylated hydroxyanisole (BHA), butylated hydroxytoluene (BHT), tert-butyl hydroquinone (TBHQ), and 2,4,6-tri-tert-butylphenol (TBP; Almeida et al., 2011; Rizwanul et al., 2014). The oxidation stability of TME was studied with Rancimat after blending with four different antioxidants (Knothe, 2001; Cremonez et al., 2016). However, the fatty-acid methyl ester composition of TME was determined on a gas chromatograph (GC) equipped with a flame ionization detector (FID) and a glass column $3.1 \mathrm{~m} \times 2.1 \mathrm{~mm}$ with a temperature range of $150-250^{\circ} \mathrm{C}$, using nitrogen as a carrier gas and di(ethylene glycol) succinate column (DEGS) by preparing the corresponding fatty-acid esters and comparing them with standard fatty-acid ester samples (Ghanei et al., 2011; Bezzera Mota Gomes Arruda et al., 2016).

\section{RESULTS AND DISCUSSIONS}

The oil content of TG seed is around $43 \%$ which makes it suitable for commercial production. However, the biodiesel yield produced after transesterification of oil has been found to be $89 \%$.

\section{Characterization of Tectona Grandis Biodiesel}

The yield of extracted oil was determined and expressed as extracted oil per $100 \mathrm{~g}$ of seeds. The fatty-acid composition of TME determined by GC is summarized in Table 1. The obtained biodiesel has $42.71 \%$ oleic acid, $13.1 \%$ palmitic acid, and $31.51 \%$ linoleic acid, which makes it suitable for commercial production of biodiesel. The high content of unsaturation keeps a balance between its cold flow properties and oxidative stability.

The important characteristics determined for TME along with raw oil and mineral diesel as per ASTM D-6751 and EN-14214 specifications are summarized in Table 2 (Tripartite Task Force, 2007; ASTM D-67511b, 2011). Many of the properties were determined in triplicate and SD for those has been reported in the tabulated data. Most of the physicochemical properties tested for TME, such as acid value, viscosity, cetane number, calorific value, cold flow properties, flash point, iodine value, and density, meet the recommended limits as per standard testing methods ASTM D-6751 and EN-14214. However, the oxidation stability for TME was found to be $3.43 \mathrm{~h}$ meeting the

TABLE 1 | Fatty-acid methyl ester composition of Tectona Grandis biodiesel by gas chromatography.

\begin{tabular}{llc}
\hline Fatty-acid methyl ester & Chemical formula & Content (wt\%) \\
\hline Palmitic & $\mathrm{C}_{16} \mathrm{H}_{32} \mathrm{O}_{2}$ & 13.10 \\
Stearic & $\mathrm{C}_{18} \mathrm{H}_{36} \mathrm{O}_{2}$ & 7.02 \\
Arachidic & $\mathrm{C}_{20} \mathrm{H}_{40} \mathrm{O}_{2}$ & 2.15 \\
Oleic & $\mathrm{C}_{18} \mathrm{H}_{34} \mathrm{O}_{2}$ & 42.71 \\
Linoleic & $\mathrm{C}_{18} \mathrm{H}_{32} \mathrm{O}_{2}$ & 31.51 \\
Linolenic & $\mathrm{C}_{18} \mathrm{H}_{30} \mathrm{O}_{2}$ & 0.47 \\
Others & - & 3.04 \\
Saturated & - & 22.27 \\
Unsaturated & - & 74.69
\end{tabular}

TABLE 2 | Physicochemical properties of TG raw oil, TG biodiesel and mineral diesel with standard limits as per ASTM D-6751 and EN-14214 specifications.

\begin{tabular}{|c|c|c|c|c|c|c|c|c|}
\hline Property (units) & $\begin{array}{l}\text { ASTM D-6751-08 } \\
\text { test method }\end{array}$ & $\begin{array}{c}\text { ASTM D-6751-08 } \\
\text { limits }\end{array}$ & $\begin{array}{c}\text { EN-14214 test } \\
\text { method }\end{array}$ & $\begin{array}{l}\text { EN-14214 } \\
\text { limits }\end{array}$ & Diesel & Raw oil & $\begin{array}{c}\text { TG } \\
\text { biodiesel }\end{array}$ & $\begin{array}{l}\text { SD for } \\
\text { TME }\end{array}$ \\
\hline Acid value (mg KOH/g) & ASTM D-664 & 0.5 & EN-14104 & 0.5 & _- & 1.96 & 0.39 & 0.064 \\
\hline lodine value (g/100 g) & - & - & EN-ISO 14111 & 120 & - & - & 96.4 & 0.97 \\
\hline Viscosity at $40^{\circ} \mathrm{C}\left(\mathrm{mm}^{2} / \mathrm{s}\right)$ & D-445 & $1.9-6.0$ & EN-ISO 3104 & $3.5-5.0$ & $1.3-4.1$ & - & 4.69 & 0.03 \\
\hline Density $\left(15^{\circ} \mathrm{C}\right)\left(\mathrm{kg} / \mathrm{m}^{3}\right)$ & - & - & EN-3675 & $860-900$ & $820-870$ & 929 & 869 & 4.94 \\
\hline Calorific value (kJ/kg) & - & - & - & - & 44800 & 35926 & 38831 & - \\
\hline Sulfated ash (\%mass) & D-874 & Max. 0.02 & EN-ISO 3987 & Max. 0.02 & - & - & 0.0021 & - \\
\hline Sulfur (\%mass) & D-5453/D-4294 & $\begin{array}{l}\text { Max. } 0.0015 \text { (S 15) } \\
\text { Max. } 0.05 \text { (S 500) }\end{array}$ & $\begin{array}{c}\text { EN-ISO } \\
20846 / 20884\end{array}$ & Max. 0.0010 & 0.05 & - & 0.004 & 0.0013 \\
\hline Cetane number & D-613 & Min. 47 & EN-ISO 5165 & Min. 51 & $40-55$ & - & 54.3 & 0.16 \\
\hline Water and sediment (vol.\%) & D-2709 & Max. 0.05 & - & - & - & - & 0.033 & 0.0049 \\
\hline Cloud point $\left({ }^{\circ} \mathrm{C}\right)$ & D-2500 & - & EN-23015 & - & - & - & 3 & - \\
\hline Pour point $\left({ }^{\circ} \mathrm{C}\right)$ & D-97 & - & EN-3016 & - & - & - & -2 & - \\
\hline Cold filter plugging point $\left({ }^{\circ} \mathrm{C}\right)$ & D-6371 & - & EN-116 & - & - & - & 1 & - \\
\hline Oxidation stability at $110^{\circ} \mathrm{C}(\mathrm{h})$ & EN-14112 & Min. $3 \mathrm{~h}$ & EN-ISO 14112 & Min. $6 \mathrm{~h}$ & - & - & 3.43 & 0.057 \\
\hline
\end{tabular}


minimum limit of $3 \mathrm{~h}$ in accordance with recent ASTM D-6751 but failed to meet standard value of $6 \mathrm{~h}$ specified by EN-14214. The poor resistance to oxidation attributed to a large percent of unsaturation in the fatty-acid chain. The features of TME except oxidation stability characterize the suitability of this crop for biodiesel production, which reflects a good prospective of TG as a feedstock for biodiesel.

\section{Effect of Antioxidants on the Oxidation Stability of TME}

Tectona methyl ester showed a poor oxidative stability due to a high-unsaturation degree in fatty-acid profile. Adding synthetic antioxidants is a common practice in the biodiesel industry to ensure satisfactory biodiesel oxidative stability. In the current study, four antioxidants BHA, BHT, TBHQ, and TBP, were doped at different fills $(50,100,150,200,250$, and $300 \mathrm{ppm})$ in TME and Rancimat test was conducted to study the effectiveness of these antioxidants. Figure 1 shows the effect of antioxidants on the induction period of biodiesel. The oxidation stability of TME is increased by the dosage of four artificial antioxidants blended in different extent. TBHQ in $300 \mathrm{ppm}$ concentration added to TME showed OS of $8.47 \mathrm{~h}$ and is considered as most effective among all other additives which can be explained on the basis of its chemical structure. TBHQ contains more -OH groups attached to its aromatic ring as compared with other employed

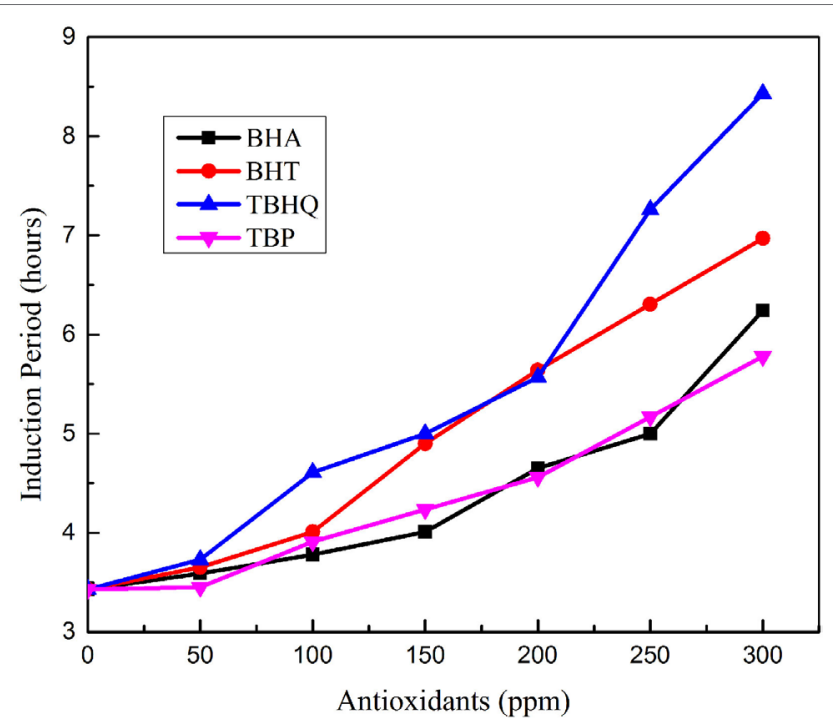

FIGURE 1 | Variation in induction period of Tectona Grandis biodiesel with antioxidant concentration.

\section{REFERENCES}

Akmal, N., and Karvekar, M. D. (2010). Isolation of phenolic compounds from the methanolic extract of Tectona grandis. Res J Pharm Biol Chem Sci. 1, 221-225.

Almeida,E.S.,Portela,F.M.,Sousa,R.M.F.,Daniel,D., Terrones,M.G.H.,Richter,E.M., et al. (2011). Behaviour of the antioxidant tert-butylhydroquinone on the storage stability and corrosive character of biodiesel. Fuel 90, 3480-3484. doi:10.1016/j.fuel.2011.06.056 antioxidants. As a result, TBHQ offers more sites for the formation of complexes between free radical and antioxidant radicals for lipid stabilization.

\section{CONCLUSION}

The adoption of fuels can be assessed in the shadow of various aspects which includes environmental impact, food issues, use of land, sustainability, and cost factor. Implementation of biodiesel from TG will lead to many advantages such as providing greenery, support to agricultural economy, reduction in dependency on imported crude oil and reduction in air pollution. The oil content of seed is $43 \%$ and biodiesel yield is $89 \%$ which makes TG seeds suitable for commercial production of biodiesel. However, the quality of any biodiesel is affected by a large number of parameters such as as fatty-acid methyl ester composition, physicochemical characteristics, and extent of oxidation. The determination of fatty-acid methyl ester composition of TME and other physicochemical characteristics of TG were carried out and found to meet the necessary limits. The fatty-acid methyl ester composition for the biodiesel is composed of $42.71 \%$ oleic acid, $13.1 \%$ palmitic acid, and $31.51 \%$ linoleic acid. Due to high content of unsaturation, the obtained biodiesel showed low oxidation stability. To address this declination, synthetic antioxidants were added to enhance the oxidation stability and oxidation stability was increased to $8.47 \mathrm{~h}$ when TBHQ was added at $300 \mathrm{ppm}$ concentration. By considering all the parameters, the present study reveals that the TG seed oil has attractive prospective in the near future for production of biodiesel. Further studies are still needed to develop a large-scale production of biodiesel.

\section{AUTHOR CONTRIBUTIONS}

AS contributed to the design of the study, drafted the manuscript, and wrote the manuscript. MS performed the experiment, contributed to the data collection, and wrote the manuscript. NS analyzed and interpreted the data and wrote the manuscript. NPS contributed to the design of the manuscript and wrote the paper.

\section{ACKNOWLEDGMENTS}

The authors acknowledge the financial support from Science and Engineering Research Board (SERB), Government of India under Grant No. SR/FTP/PS-182/2011. Authors sincerely acknowledge the ever encouraging support of IK Gujral Punjab Technical University, Kapurthala and also acknowledge the technical support provided by Mr. Mandeep Singh, Technical Assistant at Amritsar College of Engineering and Technology.

American Society for Testing and Materials. (2011). ASTM D6751-11b, Standard Specification for Biodiesel Fuel Blend Stock (B100) for Middle Distillate Fuels. West Conshohocken, PA: ASTM International.

Bezzera Mota Gomes Arruda, T., Arruda Rodrigues, F. E., Duarte Arruda, D. T., Pontes Silva Ricardo, N. M., Barbosa Dantas, M., and Costa de Araújo, K. (2016). Chromatography, spectroscopy and thermal analysis of oil and biodiesel of sesame (Sesamum indicum) - an alternative for the Brazilian Northeast. Indus. Crops Prod. 91, 264-271. doi:10.1016/j.indcrop.2016.07.029 
Chen, K. S., Lin, Y. C., Hsu, K. H., and Wang, H. K. (2012). Improving biodiesel yields from waste cooking oil by using sodium methoxide and a microwave heating system. Energy 38, 151-156. doi:10.1016/j.energy.2011.12.020

Contran, N., Chessa, L., Lubino, M., Bellavite, D., Roggero, P. P., and Enne, G. (2013). State-of-the-art of the Jatropha curcas productive chain: From sowing to biodiesel and by-products. Ind. Crops Prod. 42, 202-215. doi:10.1016/ j.indcrop.2012.05.037

Cremonez, P. A., Feroldi, M., de Jesus de Oliveira, C., Teleken, J. G., Meier, T. W., Dieter, J., et al. (2016). Oxidative stability of biodiesel blends derived from different fatty materials. Ind. Crops Prod. 89, 135-140. doi:10.1016/ j.indcrop.2016.05.004

da Silva, F. L., do Nascimento, J. R., de Melo, L. N., de Freitas, J. A. S., Bortoluzzi, J. H., and Meneghetti, S. M. P. (2017). Study of correlations between composition and physicochemical properties during methylic and ethylic biodiesel synthesis. Ind. Crops Prod. 95, 18-26. doi:10.1016/j.indcrop.2016.09.053

Fernandes, D. M., Sousa, R. M. F., de Oliveira, A., Morais, S. A. L., Richter, E. M., and Muñoz, R. A. A. (2015). Moringa oleifera: a potential source for production of biodiesel and antioxidant additives. Fuel. 146, 75-80. doi:10.1016/j. fuel.2014.12.081

Fernandez, C. M., Solana, M., Fiori, L., Rodriguez, J. F., Ramos, M. J., and Perez, A. (2015). From seeds to biodiesel: Extraction, esterification, transesterification and blending of Jatropha curcas oil. Environ. Eng. Manage. J. 14, 2855-2864.

Ghanei, R., Moradi, G. R., Kalantari, R. T., and Arjmandzadeh, E. (2011). Variation of physical properties during transesterification of sunflower oil to biodiesel as an approach to predict reaction progress. Fuel Process. Technol. 92, 1593-1598. doi:10.1016/j.fuproc.2011.04.003

Government of India. (2009). National Policy on Biofuels. Available at: http://mnre. gov.in/file-manager/UserFiles/biofuel_policy.pdf

Gui, M. M., Lee, K. T., and Bhatia, S. (2008). Feasibility of edible oil vs. non-edible oil vs. waste edible oil as biodiesel feedstock. Energy 33, 1646-1653. doi:10.1016/ j.energy.2008.06.002

Hossain, A. K., and Davies, P. A. (2013). Pyrolysis liquids and gases as alternative fuels in internal combustion engines-a review. Renew. Sustain. Energy Rev. 21, 165-189. doi:10.1016/j.rser.2012.12.031

Hu, J., Du, Z., Tang, Z., and Min, E. (2004). Study on the solvent power of a new green solvent: biodiesel. Indus. Eng. Chem. Res. 43, 7928-7793. doi:10.1021/ ie0493816

Keiding, H., Wellendorf, H., and Lauridsen, E. B. (1986). Evaluation of an International Series of Teak Provenance Trial. Humblebeak, Denmark: Danida Forest Seed Centers Publication.

Kjaer, E. D., Lauridsen, E. B., and Wellendorf, H. (1995). Second Series of an International Series of Teak Provenance Trial. Humblebeak, Denmark: Danida Forest seed center Publication.

Knothe, G. (2001). Analytical methods used in the production and fuel quality assessment of biodiesel. Trans. ASAE 44, 193-200. doi:10.13031/2013.4740

KoohiKamali, S., Tan, C. P., and Ling, T. C. (2012). Optimization of sunflower oil transesterification process using sodium methoxide. Sci. World J. 2012, 475027. doi:10.1100/2012/475027
Lane, J. W., Hukriede, K., Jersett, A., Koirala, D., Levings, D., Stewart, A., et al. (2012). Synthesis and characterization of new biodiesels derived from oils of plants growing in Northern Wisconsin and Minnesota. J. Am.Oil Chem. Soc. 89, 721-725. doi:10.1007/s11746-011-1963-0

Lin, Y. C., Hsu, K. H., and Lin, J. F. (2014). Rapid palm-biodiesel production assisted by a microwave system and sodium methoxide catalyst. Fuel 115, 306-311. doi:10.1016/j.fuel.2013.07.022

Najafi, G., Ghobadian, B., and Yusaf, T. F. (2011). Algae as a sustainable energy source for biofuel production in Iran: a case study. Renew. Sustain. Energy Rev. 15, 3870. doi:10.1016/j.rser.2011.07.010

Rizwanul, I. M., Masjuki, H. H., Kalam, M. A., and Masum, B. M. (2014). Effect of synthetic antioxidants on storage stability of Calophyllum inophyllum biodiesel. Mater. Res. Innov. 18, S6-S90. doi:10.1179/1432891714Z.000000000936

Sarin, A. (2012). Biodiesel Production and Properties. London: RSC Publications.

Sarin, A., Arora, R., Singh, N. P., Sarin, R., Malhotra, R. K., and Sarin, S. (2010). Blends of biodiesels synthesized from non edible and edible oils: effects on the cold filter plugging point. Energy Fuels 24, 1996-2001. doi:10.1021/ ef901131m

Silitonga, A. S., Masjuki, H. H., Ong, H. C., Yusaf, T., Kusumo, F., and Mahlia, T. M. I. (2016). Synthesis and optimization of Hevea brasiliensis and Ricinus communis as feedstock for biodiesel production: a comparative study. Ind. Crops Prod. 85, 274-286. doi:10.1016/j.indcrop.2016.03.017

Silveira, E. G., Simionatto, E., Perez, V. H., Justo, O. R., Zarate, N. A. H., and Vieira, M. D. C. (2016). Potential of Virginia-type peanut (Arachis hypogaea L.) as feedstock for biodiesel production. Ind. Crops Prod. 89, 448-454. doi:10.1016/ j.indcrop.2016.04.050

Singh, J., Bhuyan, T. C., and Ahmed, A. (1996). Ethnobotanical studies on the Mishing tribes of Assam with special reference to food and medicinal plant. J Eco Tax Bot. 12, 350-356.

Tripartite Task Force. (2007). White Paper on Internationally Compatible Biofuel Standards. Brazil: European Union \& United States of America.

Ullah, Z., Bustam, M. A., and Man, Z. (2014). Characterization of waste palm cooking oil for biodiesel production. Int. J. Chem. Eng. Appl. 5, 134-137. doi:10.7763/IJCEA.2014.V5.366

Yang, J., He, Q. S., Corscadden, K., and Caldwell, C. (2017). Improvement on oxidation and storage stability of biodiesel derived from an emerging feedstock camelina. Fuel Process. Technol. 157, 90-98. doi:10.1016/j.fuproc.2016. 12.005

Conflict of Interest Statement: The authors declared no potential conflicts of interest with respect to the research, authorship, and/or publication of this article.

Copyright (c) 2017 Sarin, Singh, Sharma and Singh. This is an open-access article distributed under the terms of the Creative Commons Attribution License (CC BY). The use, distribution or reproduction in other forums is permitted, provided the original author(s) or licensor are credited and that the original publication in this journal is cited, in accordance with accepted academic practice. No use, distribution or reproduction is permitted which does not comply with these terms. 